\title{
Influence of the Base Element on the Thermal Properties of Non- Ferrous Chromium-Rich TaC-Containing Alloys Elaborated by Conventional Casting: Part 3: Surface and Cross-Sectional Metallographic Characterization of the Oxidized Alloys
}

\author{
Jean-Paul K. Gomis ${ }^{1}$, Patrice Berthod ${ }^{2, *}$ and Erwann Etienne ${ }^{2}$ \\ ${ }^{1}$ Faculty of Science and Technologies, Campus Victor Grignard, Rue du Jardin Botanique, BP 7023954500 \\ Vandoeuvre-lès-Nancy, France \\ ${ }^{2}$ Institut Jean Lamour (UMR 7198), University of Lorraine, Campus ARTEM, 2 allée André Guinier, BP 50840, \\ 54000 Nancy, France
}

\begin{abstract}
The six alloys the thermal properties of which and the tendency to oxide spallation of which were studied in the first two parts of this work, were here characterized after oxidation for 70 hours at $1250^{\circ} \mathrm{C}$. The external chromia scale, and also the $\mathrm{CrTaO}_{4}$ subsurface oxide, formed for all the alloys, almost independently of the Co and $\mathrm{Ni}$ proportions in the base element content. But, because of the formation of more $\mathrm{CrTaO}_{4}$ for the nickel-richest alloys probably due to the higher availability of $\mathrm{Ta}$ in the matrix and its easier diffusion towards the neighbourhood of the oxidation front, the adherence of chromia was weakened and spallation, suggested by the thermogravimetric curves in the second part of this work, is here really observed and the denuded part of alloys clearly seen. The degradation of the subsurface, which can be in a first time summarized by the development of a carbide-free zone and a $\{\mathrm{Cr}$, Ta\}-depleted zone, depends on the $\mathrm{Co}$ and Ni proportions. The microstructure of the bulk is differently affected by long exposure at elevated temperature. The changes in carbide population characteristics are stronger for the nickel-based alloys than for the cobalt-based ones. Finally, the isothermal oxidation behaviour is best for the nickel-richest alloys but the oxide spallation behaviour and the potential mechanical properties are the best for the cobalt-richest alloys.
\end{abstract}

Keywords: Cast alloys for high temperature, nickel and cobalt, tantalum carbides, oxide surface characterization, subsurface deterioration characterization.

\section{INTRODUCTION}

The conventionally equi-axed cast superalloys' family exists since many decades $[1,2]$ and but is today still relevant [3]. Among the oldest ones the chromium-rich nickel-based alloys and cobalt-based ones are the most important. For the same bases new metallurgical systems have replaced the old principles of strengthening by chromium carbides, as equi-axed alloys reinforced by a mix of carbides including tantalum carbides $(\mathrm{TaC})[4,5]$ or TaC-reinforced directionally solidified versions $[6,7]$. When chromium carbides rather rapidly change in morphology and volume fraction during exposure at very high temperatures (higher than $1000^{\circ} \mathrm{C}$ ) $\mathrm{TaC}$ carbides remains more stable although they may suffer themselves degradation near $1200^{\circ} \mathrm{C}$ [8]. Tantalum (and also carbon) being rather easy to oxidize at high temperature [9, 10], TaC (and other MC carbides) were under interest for hot oxidation studies to investigate their specific behaviour [11-13].

The alloys subject of the present study all contain close to $6 \mathrm{wt}$ \% Ta and are more or less rich in tantalum

Address correspondence to this article at the Institut Jean Lamour (UMR 7198), University of Lorraine, Campus ARTEM, 2 allée André Guinier, BP 50840, 54000 Nancy, France; Tel: (+33) 3727427 29;

E-mail: patrice.berthod@univ-lorraine.fr carbides. The presence of these highly oxidable carbides, furthermore mainly in the grain boundaries and in the interdendritic spaces which are fast chromium diffusion ways in situation of oxidation at high temperature, certainly influence strongly the behaviour of these alloys, regardless to the base element (nickel and/or cobalt). So, after a first part [14] devoted to the thermal properties of a series of six chromium-rich TaC-rich cast alloys with varying proportions in $\mathrm{Ni}$ and $\mathrm{Co}$, and second part [15] in which a first aspect of high temperature oxidation behaviour (phenomena at heating and cooling), this is here the isothermal oxidation behaviour which will be here investigated, exclusively by metallographic characterization. Knowing that cobalt alloys are generally less hot corrosion resistant than nickel alloys for similar compositions for the other elements, the question to answer is how the presence of Ta in high content and the form with which it is present may influence this hierarchy.

\section{MATERIALS AND METHODS}

\section{Reminders on the Studied Alloys}

The six alloys, the common base of which is $25 \mathrm{wt} . \% \mathrm{Cr}, 0.4 \mathrm{wt} . \% \mathrm{C}$ and $6 \mathrm{wt} . \% \mathrm{Ta}$, are different from 
one another concerning the nature and the contents in base element: from a Ni-based Co-free initial version (Ni(bal.)-25Cr-0.4C-6Ta, named "0Co5NiTa"), about 14 wt.\%Co was added several times at the expense of nickel, until achieving a total replacement (Co(bal.)$25 \mathrm{Cr}-0.4 \mathrm{C}-6 \mathrm{Ta}$, named "5CoONiTa"). These six alloys were elaborated from pure elements by foundry way (high frequency induction melting, cooling in a cooled copper crucible, under argon atmosphere), this leading to 6 ingots all weighing about 40 grams. The obtained as-cast microstructures, specified in the first part [14] of this work, are all dendritic and contain carbides, exclusively located in the grain boundaries and interdendritic spaces. These carbides are either chromium carbides and tantalum carbides (case of the $\mathrm{Ni}$-richest alloys), or tantalum carbides only (case of the Co-richest ones). Their morphologies suggest that chromium carbides and tantalum carbides are separately part of two eutectic compounds, both with matrix as second phase.

\section{Tests in Oxidation at High Temperature}

Ingots' cutting and surface grinding of the obtained parts of alloys led to thermogravimetry samples which were all subjected to a thermal cycle composed of a heating at $+20^{\circ} \mathrm{C} / \mathrm{min}$, a 70 hours isothermal stage at $1250^{\circ} \mathrm{C}$ and a cooling at $-5^{\circ} \mathrm{C} / \mathrm{min}$. The atmosphere was a flowing synthetic air composed of $80 \% \mathrm{O}_{2}$ and $20 \% \mathrm{~N}_{2}$. At the end of the experiment the oxidized samples were first subjected to a surface analysis (naked eye observation with assessment of the oxide scale spallation, and X-ray spectrometry). These results were previously presented in the second part of this work [15].

\section{Electron Microscopy Observation Characterization of the Oxidized Surfaces}

and

The characterization of the surface of the six oxidized samples prior to cross sectional preparation was continued in the present part of the work, by examining these oxidized surfaces using a Scanning Electron Microscope (SEM, JEOL JSM-6010LA) and its attached Energy Dispersion Spectrometer (EDS). The necessity of having an extreme surface electrically conductive led to apply thin metallic deposit. This was done by cathodic pulverisation of gold. The surfaces and the oxides covering them were thereafter observed with the SEM in Secondary Electrons (SE) mode to have a rather deep zone of neatness. EDS was attempted in zone and particles presenting a local sufficient flat surface, in order to identify the elements which were the most present, after deduction of the gold contribution, and then the types of oxides present. This also allowed estimating the chemical compositions of the alloys in extreme surface where oxide spallation denuded them. Per sample a area was also chosen to be subjected to X-ray mapping to have a global look of the oxides distributions and morphologies.

\section{Cross Sectional Characterization of the External Oxides and of the Deteriorated Sub-Surfaces}

The samples were thereafter embedded, then cut. Grinding (using SiC papers from \#240 to \#1200) and polishing (textile disk with $1 \mu \mathrm{m}$ hard particles) led to mirror-like samples authorizing cross sectional characterization. SEM observations in Back Scattered Electrons mode (BSE), spot EDS analyses and EDS concentration profiles were carried out to clearer identify what were the oxides remained on surface, to characterize the degradation state of the subsurface and the local microstructure and chemical consequences of oxidation. A look was also taken at the microstructure in the bulk, to know how it evolved during the exposure at high temperature.

\section{RESULTS AND DISCUSSION}

\section{Surface States Observed with the SEM in SE Mode before Cross Sections Preparation}

The oxidation states of the surfaces of the samples subjected to $70 \mathrm{~h}$ in synthetic at $1250^{\circ} \mathrm{C}$ are illustrated by SEM/SE micrographs, in Figure $\mathbf{1}$ for the two nickelrichest alloys (left: $0 \mathrm{Co} 5 \mathrm{NiTa}$, bottom: $1 \mathrm{Co} 4 \mathrm{NiTa}$, top: $\times 250$, bottom: $\times 1000$ ), Figure 2 for the two intermediate alloys $2 \mathrm{Co} 3 \mathrm{NiTa}$ (left) and $3 \mathrm{Co} 2 \mathrm{NiTa}$ (right) and Figure 3 for the two cobalt-richest alloys 4Co1NiTa (left) and $5 \mathrm{CoONiTa}$ (right). One can see that the main oxide to be seen on surface is the complex $\mathrm{CrTaO}_{4}$ one for the $0 \mathrm{Co} 5 \mathrm{NiTa}$ and $1 \mathrm{Co} 4 \mathrm{NiTa}$ alloys the surface of which is denuded elsewhere. In the $\times 1000$ micrograph of the OCoNiTa one clearly distinguish the cups-shape of the denuded alloy as well as double and triple interdendritic boundaries. Chromia $\left(\mathrm{Cr}_{2} \mathrm{O}_{3}\right)$ starts to be visible on the micrographs of the two intermediate alloys, together with $\mathrm{CrTaO}_{4}$ and the spinel oxide $(\mathrm{Ni}, \mathrm{Co}) \mathrm{Cr}_{2} \mathrm{O}_{4}$ or $\mathrm{CoCr}_{2} \mathrm{O}_{4}$. In addition to the formers $(\mathrm{Ni}, \mathrm{Co}) \mathrm{O}$ or $\mathrm{CoO}$ can be observed additionally on the surfaces of the two cobalt-richest alloys $4 \mathrm{Co} 1 \mathrm{NiTa}$ and $5 \mathrm{CoONiTa}$. A Xmap is also presented, in Figure 4. One can see a chromia area and a denuded alloy area.

The observations made about the oxidized surface states of the six alloys, prior to the cross-sectional 


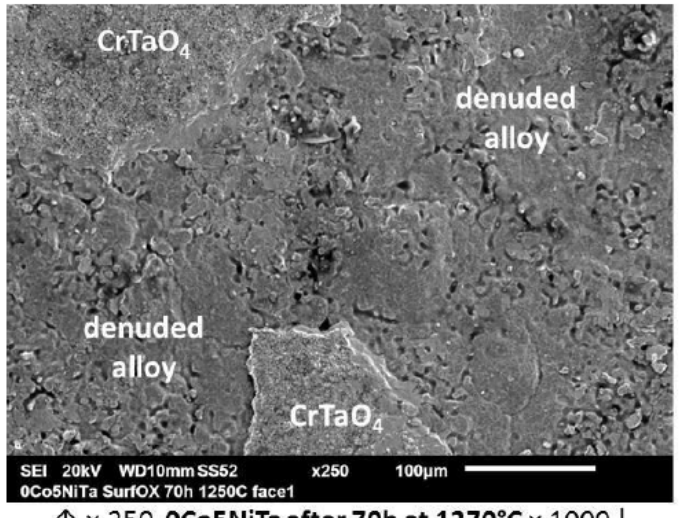

$\uparrow \times 250$ 0Co5NiTa after $70 \mathrm{~h}$ at $1270^{\circ} \mathrm{C} \times 1000 \downarrow$

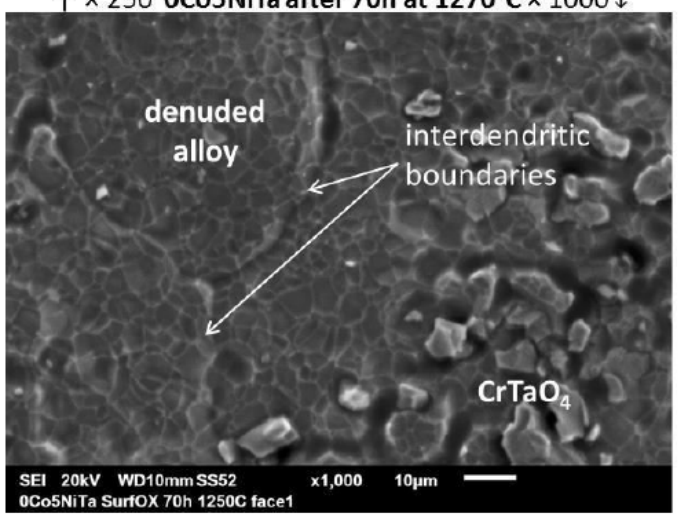

Figure 1: Surface states of the oxidized $0 \mathrm{Co} 5 \mathrm{NiTa}$ (left) and 1 Co4NiTa (right) alloys at two magnifications: general view at $\times 250$ (top) and detailed view at $\times 1000$ (bottom).
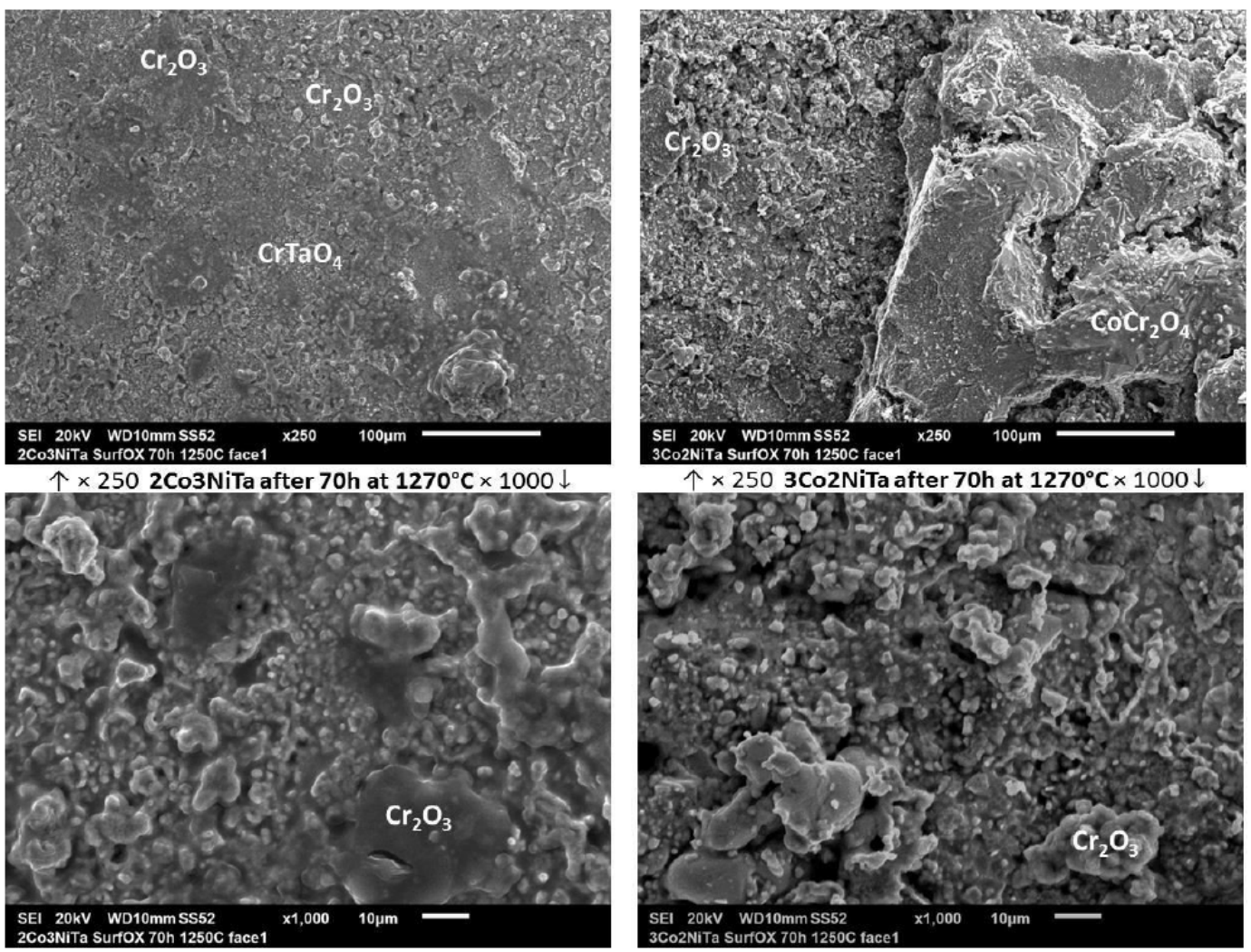

$\uparrow \times 2503 \mathrm{Co} 2 \mathrm{NiTa}$ after $70 \mathrm{~h}$ at $1270^{\circ} \mathrm{C} \times 1000 \downarrow$

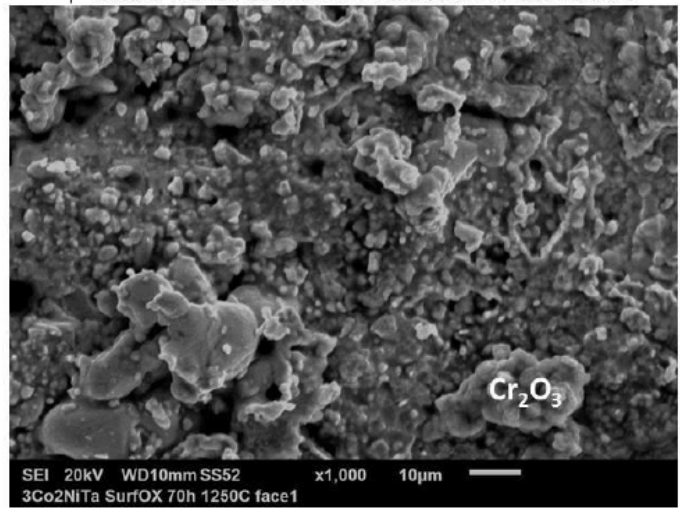

Figure 2: Surface states of the oxidized $2 \mathrm{Co} 3 \mathrm{NiTa}$ (left) and 3Co2NiTa (right) alloys at two magnifications: general view at $\times 250$ (top) and detailed view at $\times 1000$ (bottom). 


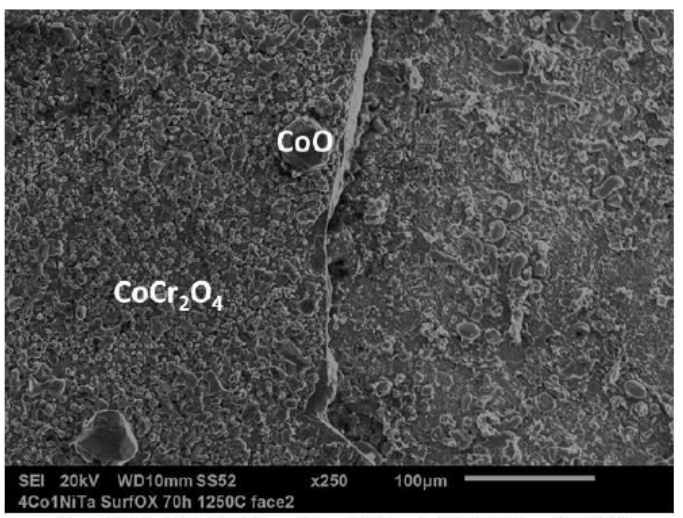

$\uparrow \times 2504 \mathrm{Co} 1 \mathrm{NiTa}$ after $70 \mathrm{~h}$ at $1270^{\circ} \mathrm{C} \times 1000 \downarrow$

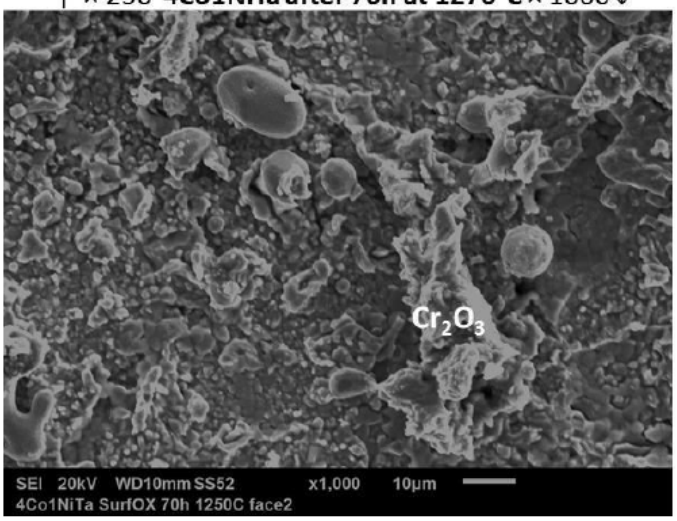

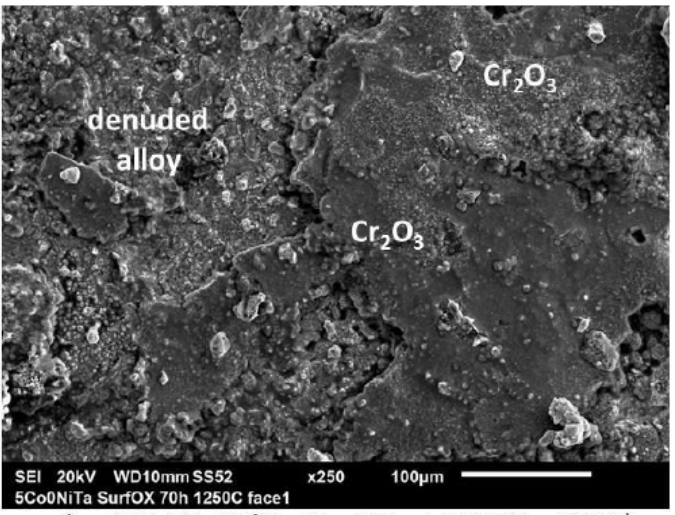

$\uparrow \times 250$ 5CoONiTa after $70 \mathrm{~h}$ at $1270^{\circ} \mathrm{C} \times 1000$

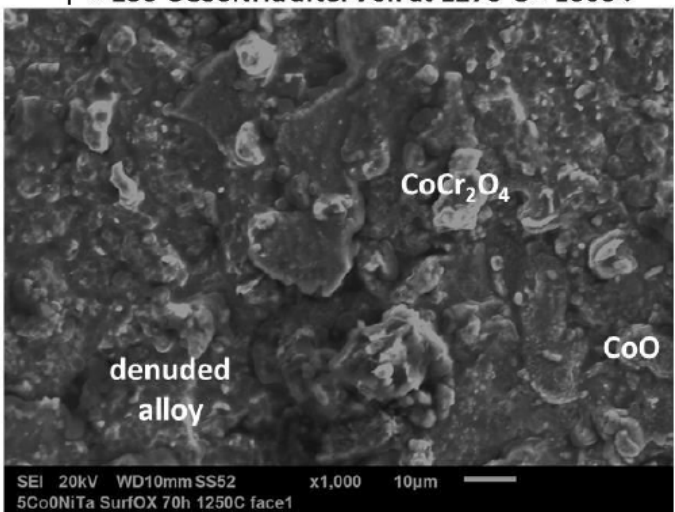

Figure 3: Surface states of the oxidized $4 \mathrm{Co} 1 \mathrm{NiTa}$ (left) and $5 \mathrm{Co} 0 \mathrm{NiTa}$ (right) alloys at two magnifications: general view at $\times 250$ (top) and detailed view at $\times 1000$ (bottom).
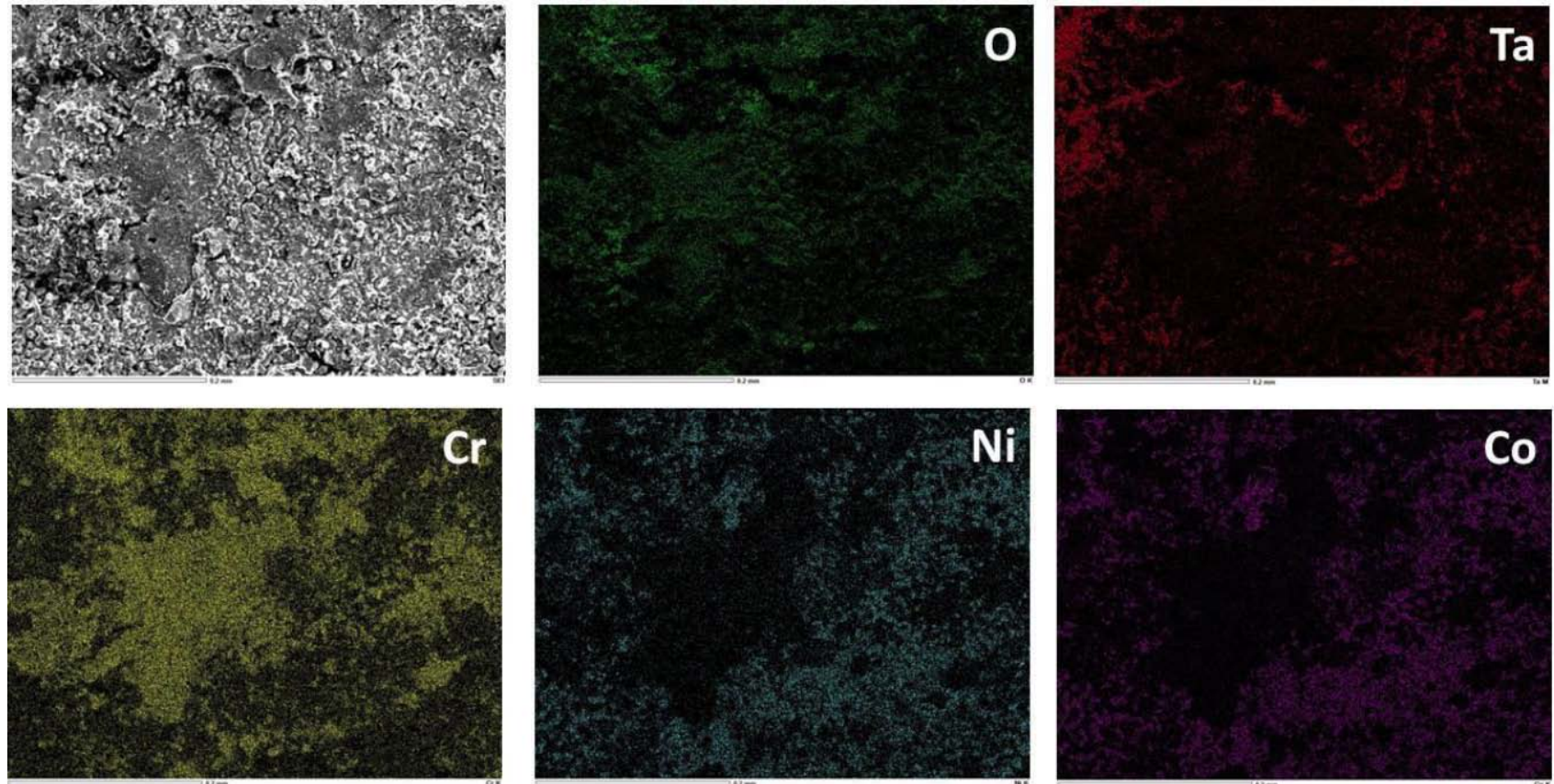

$3 \mathrm{Co} 2 \mathrm{NiTa}$ after $70 \mathrm{~h}$ at $1270^{\circ} \mathrm{C}$

Figure 4: X-map of an area of the oxidized surface of one of the alloys (here: 3Co2NiTa).

characterization can be summarized by the content of Table 1. The complex oxide $\mathrm{CrTaO}_{4}$ obviously formed on the surface or very close to the surface in all cases.
Chromia $\left(\mathrm{Cr}_{2} \mathrm{O}_{3}\right)$ was observed on the surface of all alloys but was often absent on the $0 \mathrm{Co} 5 \mathrm{NiTa}$ alloy. $\mathrm{NiO}$ was seen on the oxidized surface of the same 
Table 1: Inventory of the Oxides Seen with the SEM in SE Mode and Identified by EDS on the Surfaces of the Oxidized Samples Before Cutting for Obtaining Cross Sections; Content Ranges in $\mathrm{Cr}$ and Ta on the Denuded Alloy Parts of Surface

\begin{tabular}{|c|c|c|c|c|c|c|}
\hline Alloy Areas & 0Co5NiTa & 1Co4NiTa & 2Co3NiTa & 3Co2NiTa & 4Co1NiTa & 5Co0NiTa \\
\hline \hline$(\mathrm{Co}, \mathrm{Ni}) \mathrm{O}$ & $\mathrm{NiO}$ & $/$ & $/$ & $/$ & $\mathrm{X}, \mathrm{CoO}$ & $\mathrm{CoO}$ \\
\hline$(\mathrm{Co}, \mathrm{Ni}) \mathrm{Cr}_{2} \mathrm{O}_{4}$ & $/$ & $/$ & $\mathrm{X}$ & $\mathrm{X}, \mathrm{CoCr}_{2} \mathrm{O}_{4}$ & $\mathrm{CoCr}_{2} \mathrm{O}_{4}$ \\
\hline $\mathrm{Cr}_{2} \mathrm{O}_{3}$ & $/$ & $\mathrm{X}$ & $\mathrm{X}$ & $\mathrm{X}$ \\
\hline $\mathrm{CrTaO}_{4}$ & $\mathrm{X}$ & $\mathrm{X}$ & $\mathrm{X}$ & $\mathrm{X}$ \\
\hline Denuded alloy & $\mathrm{X}$ & $\mathrm{X}$ & $\mathrm{X}$ & $\mathrm{X}$ \\
\hline $\begin{array}{c}\text { (wt.\%Cr} \text { and } \\
\text { wt.\%Ta) }\end{array}$ & $\begin{array}{c}(17.5-21.5 \mathrm{Cr}, 0- \\
0.9 \mathrm{Ta})\end{array}$ & $\begin{array}{c}(17.3-18.4 \mathrm{Cr}, 1.3 \\
-2.0 \mathrm{Ta})\end{array}$ & $\begin{array}{c}(17.2-19.2 \mathrm{Cr}, 0- \\
1.8 \mathrm{Ta})\end{array}$ & $(12.1 \mathrm{Cr}, 0.0 \mathrm{Ta})$ & $\begin{array}{c}(15.0-15.8 \mathrm{Cr}, 0.0 \\
-1.3 \mathrm{Ta})\end{array}$ & $\begin{array}{c}(10.0-20.0 \mathrm{Cr}, \\
0.0-0.6 \mathrm{Ta})\end{array}$ \\
\hline
\end{tabular}

$0 \mathrm{Co} 5 \mathrm{NiTa}$ alloy while (Co, $\mathrm{Ni}) \mathrm{O}$ or $\mathrm{CoO}$, as well as the spinel $(\mathrm{Co}, \mathrm{Ni}) \mathrm{Cr}_{2} \mathrm{O}_{4}$ or $\left.\mathrm{CoCr}_{2} \mathrm{O}_{4}\right)$, were present on the oxidized $4 \mathrm{Co} 1 \mathrm{NiTa}$ alloy, and only $\mathrm{CoO}$ on the $5 \mathrm{Co} 1 \mathrm{NiTa}$ one. It seems thus that the MO oxides only formed on the Ni-richest alloy (NiO seen here for $0 \mathrm{Co} 5 \mathrm{NiTa}$ but not according to XRD [15]) and on the two Co-richest alloys (consistent with the XRD results [15]). (Co,Ni)O and CoO reacted with chromia to form the corresponding spinel oxide on the two Co-richest alloys.

\section{Surface States Observed with the SEM in BSE Mode on Cross Sections}

The $\times 1000$ SEM/BSE micrographs presented in Figure 5 (for the three nickel-richest alloys) and in
Figure 6 (the three cobalt-richest alloys) show the oxides found on surface and in the subsurface very

close to the oxide scale/alloy interface. One can see that all oxides except the complex oxide of chromium and tantalum formed outside, while the later $\left(\mathrm{CrTaO}_{4}\right)$ is present in high quantities close to the interface.

Enlarged views are given in Figure 7 (the three $\mathrm{Ni}$ richest alloys) and Figure 8 (the three Co-richest alloys). They show that $\mathrm{CrTaO}_{4}$ is everywhere along the surface concentrated in the extreme subsurface of the alloys, this allowing its detection by both XRD [15] and SEM/EDS (here). These enlarged micrographs also illustrate that the external oxide scale, mainly made of chromia, generally remained more on the
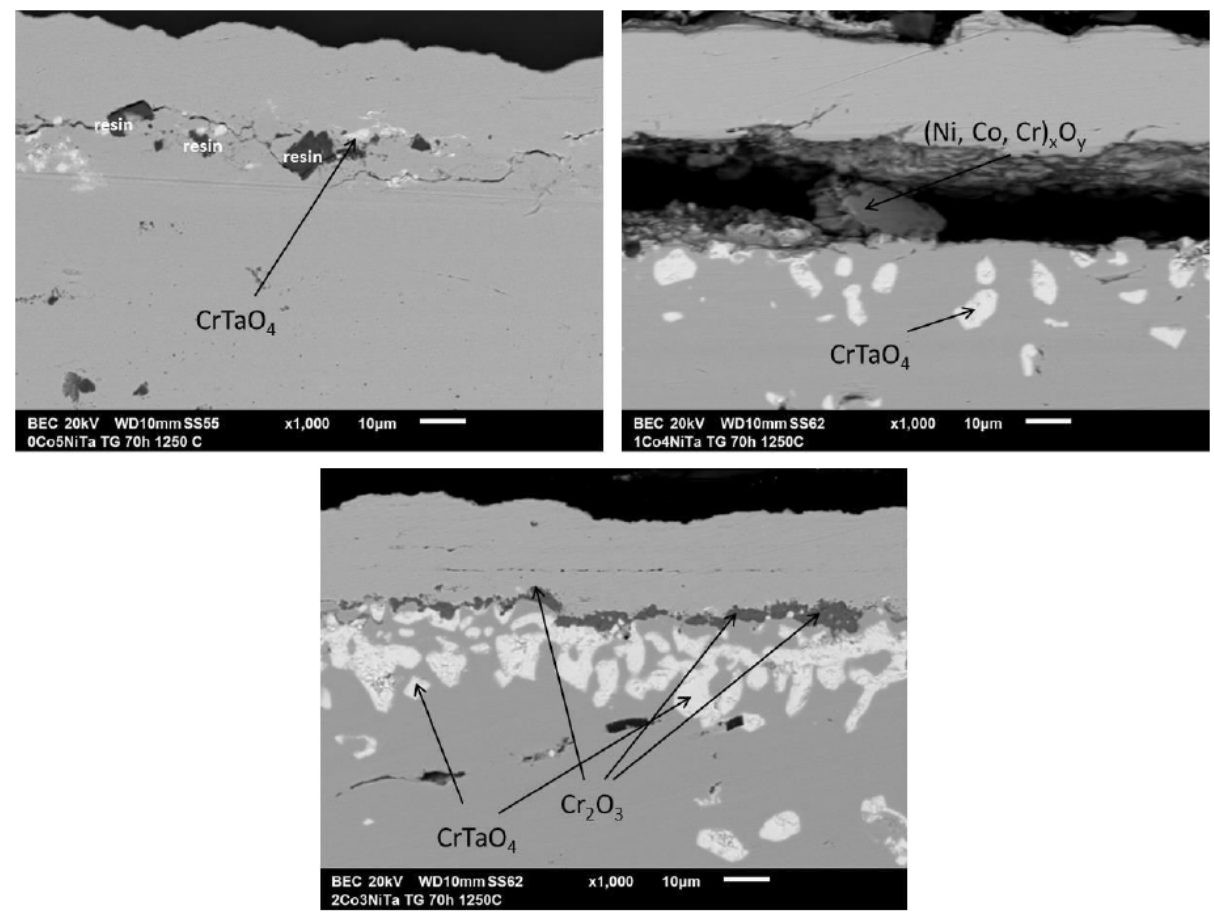

Figure 5: Surface states of the $0 \mathrm{Co} 5 \mathrm{NiTa}$ (top, left), $1 \mathrm{Co} 4 \mathrm{NiTa}$ (top, right) and $2 \mathrm{Co} 3 \mathrm{NiTa}$ (bottom) alloys after $70 \mathrm{~h}$ at $1250^{\circ} \mathrm{C}$ in air (SEM/BSE, magnification ×1000). 


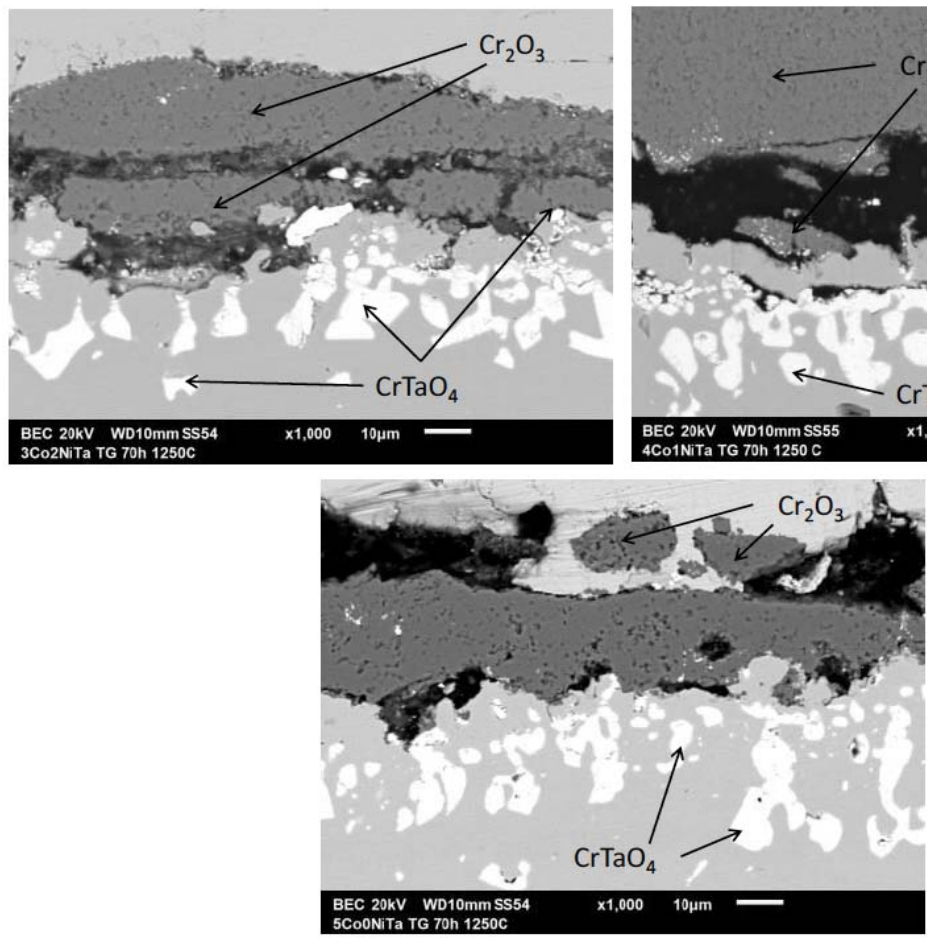

Figure 6: Surface states of the $3 \mathrm{Co} 2 \mathrm{NiTa}$ (top, left), $4 \mathrm{Co} 1 \mathrm{NiTa}$ (top, right) and $5 \mathrm{Co} 0 \mathrm{NiTa}$ (bottom) alloys after $70 \mathrm{~h}$ at $1250^{\circ} \mathrm{C}$ in air (SEM/BSE, magnification $\times 1000)$.
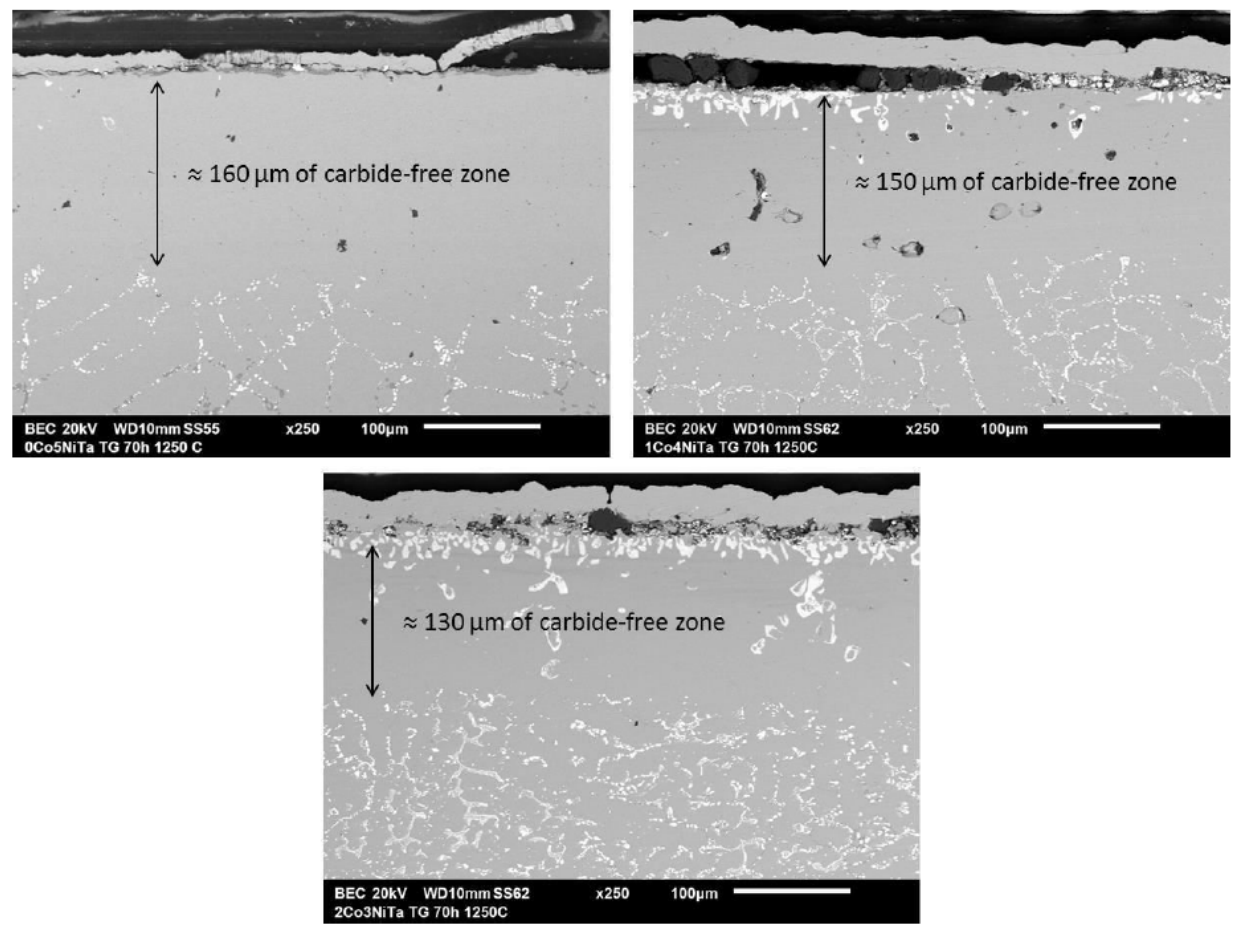

Figure 7: Sub-surface states of the 0Co5NiTa (top, left), 1Co4NiTa (top, right) and 2Co3NiTa (bottom) alloys after 70h at $1250^{\circ} \mathrm{C}$ in air (SEM/BSE, magnification $\left.\times 250\right)$.

cobalt-richest alloys than on the nickel-richest ones. One these same enlarged micrographs one can also observe that the carbides disappeared over a significant depth in the subsurface of all alloys; seemingly more extended for the Ni-richest alloys (average about 160, 150 and $130 \mu \mathrm{m}$ for the $0 \mathrm{Co} 5 \mathrm{NiTa}$, $1 \mathrm{Co} 4 \mathrm{NiTa}$ and $2 \mathrm{Co} 3 \mathrm{NiTa}$ alloys respectively) than for the Co-richest ones $(125,115$ and $110 \mu \mathrm{m}$ for the $3 \mathrm{Co} 2 \mathrm{NiTa}, 4 \mathrm{Co} 1 \mathrm{NiTa}$ and $5 \mathrm{Co} 0 \mathrm{NiTa}$ alloys). 


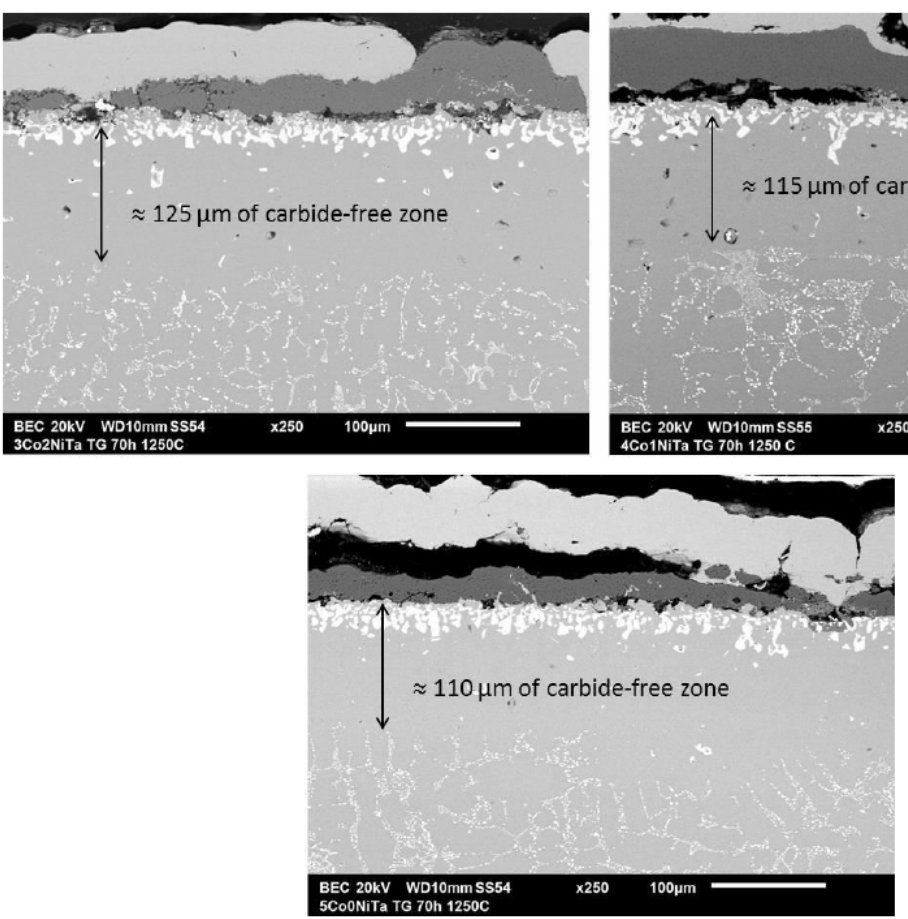

Figure 8: Sub-surface states of the $3 \mathrm{Co} 2 \mathrm{NiTa}$ (top, left), 4Co1NiTa (top, right) and $5 \mathrm{Co} 0 \mathrm{NiTa}$ (bottom) alloys after $70 \mathrm{~h}$ at $1250^{\circ} \mathrm{C}$ in air (SEM/BSE, magnification $\left.\times 250\right)$.
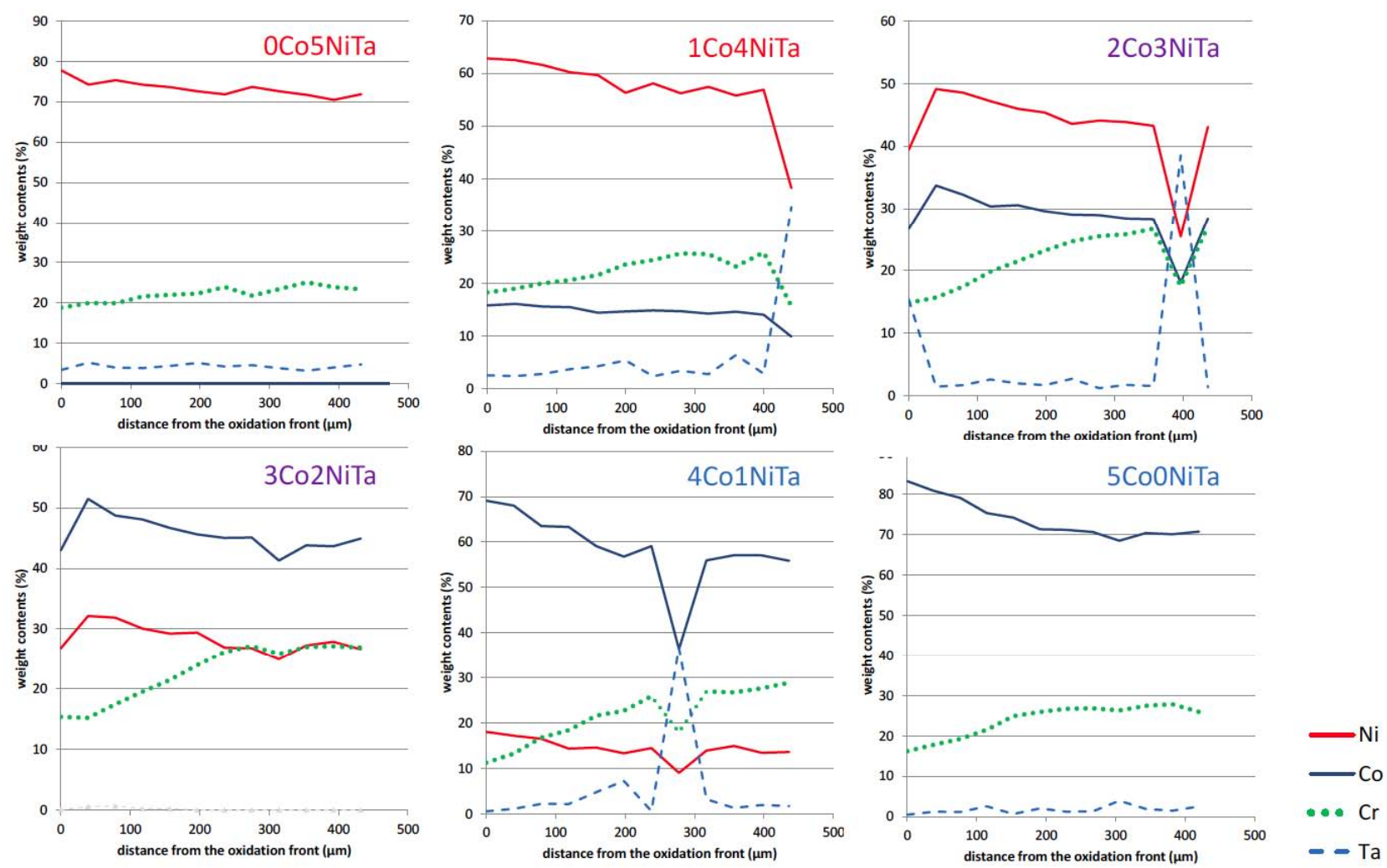

Figure 9: Concentration profiles of all elements, and notably of $\mathrm{Cr}$ and $\mathrm{Ta}$, from the oxide scale / alloy interface and perpendicularly to this interface.

Some concentrations profiles were measured and the results plotted in Figure 9. One can see that zones depleted in $\mathrm{Cr}$ and in $\mathrm{Ta}$ developed from the oxide scale/alloy interface in each case. The $\mathrm{Cr}$ depleted depth and the $\mathrm{Cr}$ and $\mathrm{Ta}$ contents on extreme surface (in alloy, close to the scale/alloy interface) both 
decrease when there is more and more cobalt replacing nickel as base element in the alloy. At the same time the chromium concentration gradient increases.

This suggests a more and more difficult diffusion of $\mathrm{Cr}$ towards the oxidation front, which is a well-known phenomenon: $\mathrm{Cr}$ diffuses faster in a Ni-based matrix than in a Co-based one. Obviously this seems to be possibly also true for tantalum. Because of the Coinduced difficulty of diffusion chromium may encounter some problem to correctly feed the oxidation front in chromia-former element, with as probable consequence le more or less late loss of the chromiaforming behaviour which allows alloys resisting oxidation and corrosion. In contrast, due to the similar Co-induced difficulty of diffusion tantalum remains at a rather high level in matrix close to the oxidation front which limits the tendency of tantalum carbides to dissolve under the remote effect of oxidation. One can also imagine that an effect of this difference in $\mathrm{Ta}$ diffusion, and thus in $\mathrm{CrTaO}_{4}$ formation in the extreme surface of alloy, may influence the adherence of the external scale of oxides: not so unfavourable for the Co-richest alloys than for the Ni-richest alloys the external scale spalled off more.
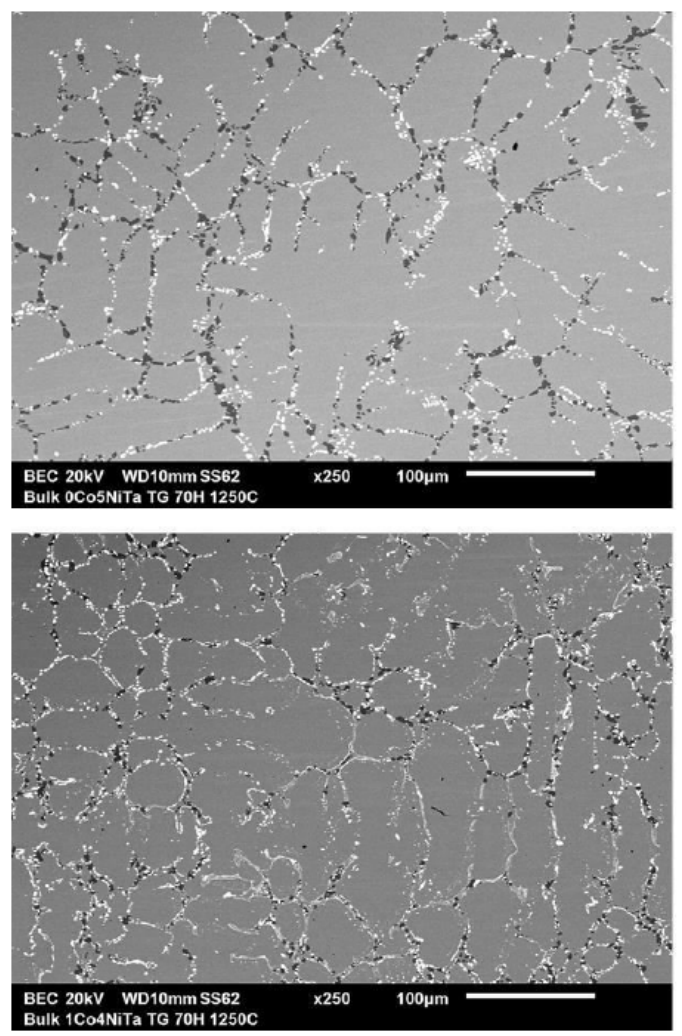

\section{Microstructure Evolutions in the Bulk}

The bulk microstructures of all alloys after the oxidation tests were also examined. The new microstructure states are illustrated by SEM/BSE micrographs in Figure $\mathbf{1 0}$ for the two Ni-richest alloys, Figure $\mathbf{1 1}$ for the two intermediate alloys and Figure $\mathbf{1 2}$ for the two Co-richest alloys. One can see that 70 hours spent at $1250^{\circ} \mathrm{C}$ induced both coarsening / coalescence of the chromium carbides and fragmentation for the tantalum carbides. The three nickel-richest alloys contain again two types of carbides, $\mathrm{Cr}_{7} \mathrm{C}_{3}$ and $\mathrm{TaC}$ in this stable state while the three cobalt-richest ones contain only $\mathrm{TaC}$ as carbide phase. This is again more or less consistent with the thermodynamic prediction of Thermo-Calc [16] working with the same database $[17,18]$ as in the first part of this work [14]. One can remark that the $\mathrm{TaC}$ populations of the Co-richest alloys are the most resistant against the effect of high temperature applied a long time and thus the most favourable to high level of mechanical properties at this elevated temperature.

\section{CONCLUSIONS}

The SEM characterization of the oxidized surface of the studied alloy allows to know more about the high
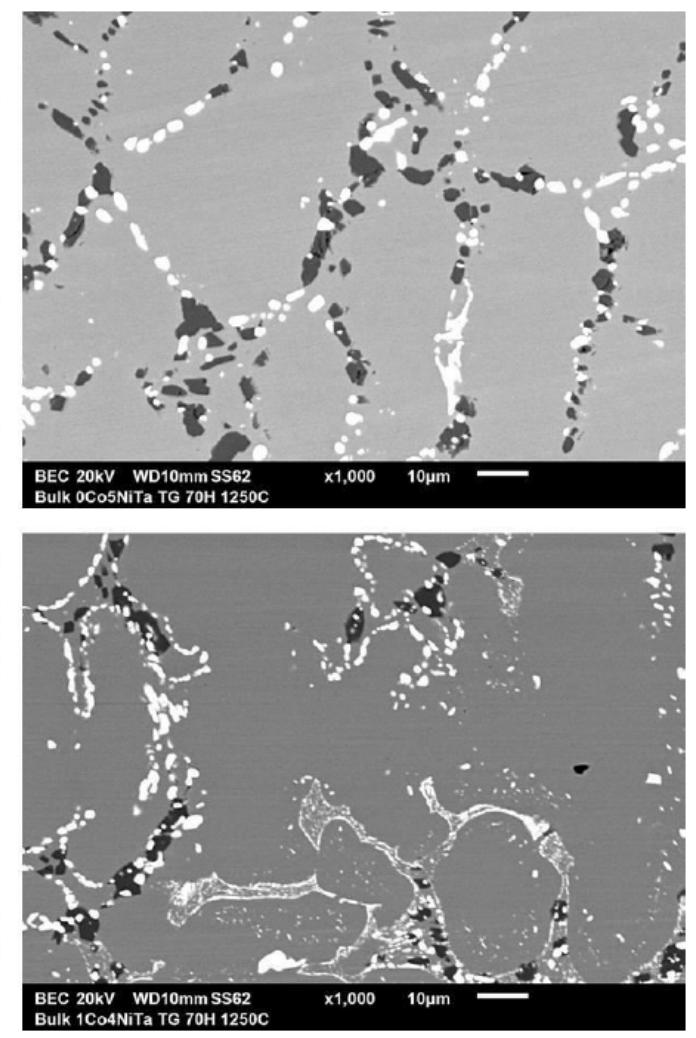

Figure 10: The new bulk microstructures of the two nickel-richest alloys (0Co5NiTa: top, 1Co4NiTa: bottom, $\times 250$ : left, $\times 250$ : right). 

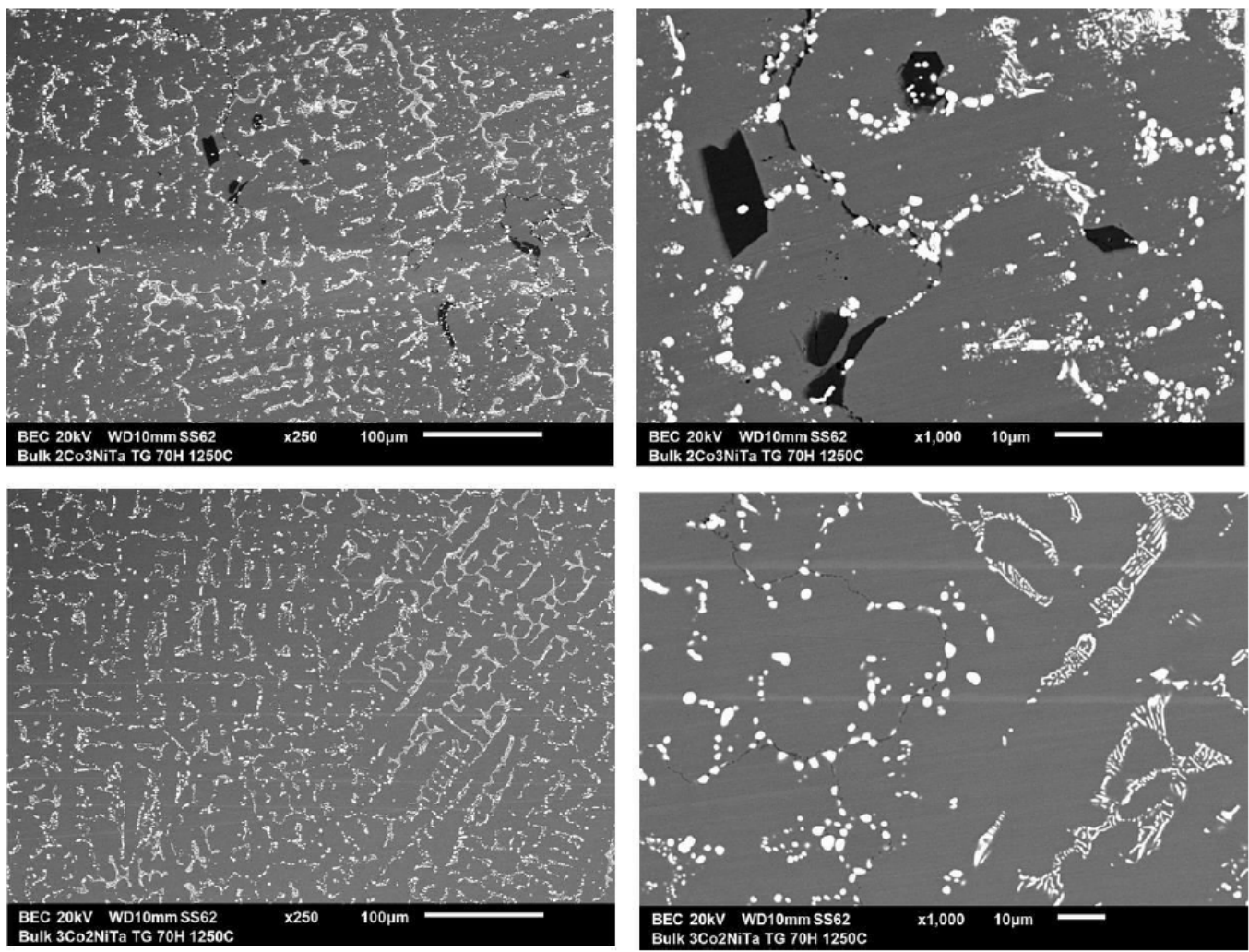

Figure 11: The new bulk microstructures of the two intermediate alloys (2Co3NiTa: top, 3Co2NiTa: bottom, $\times 250$ : left, $\times 250$ : right).
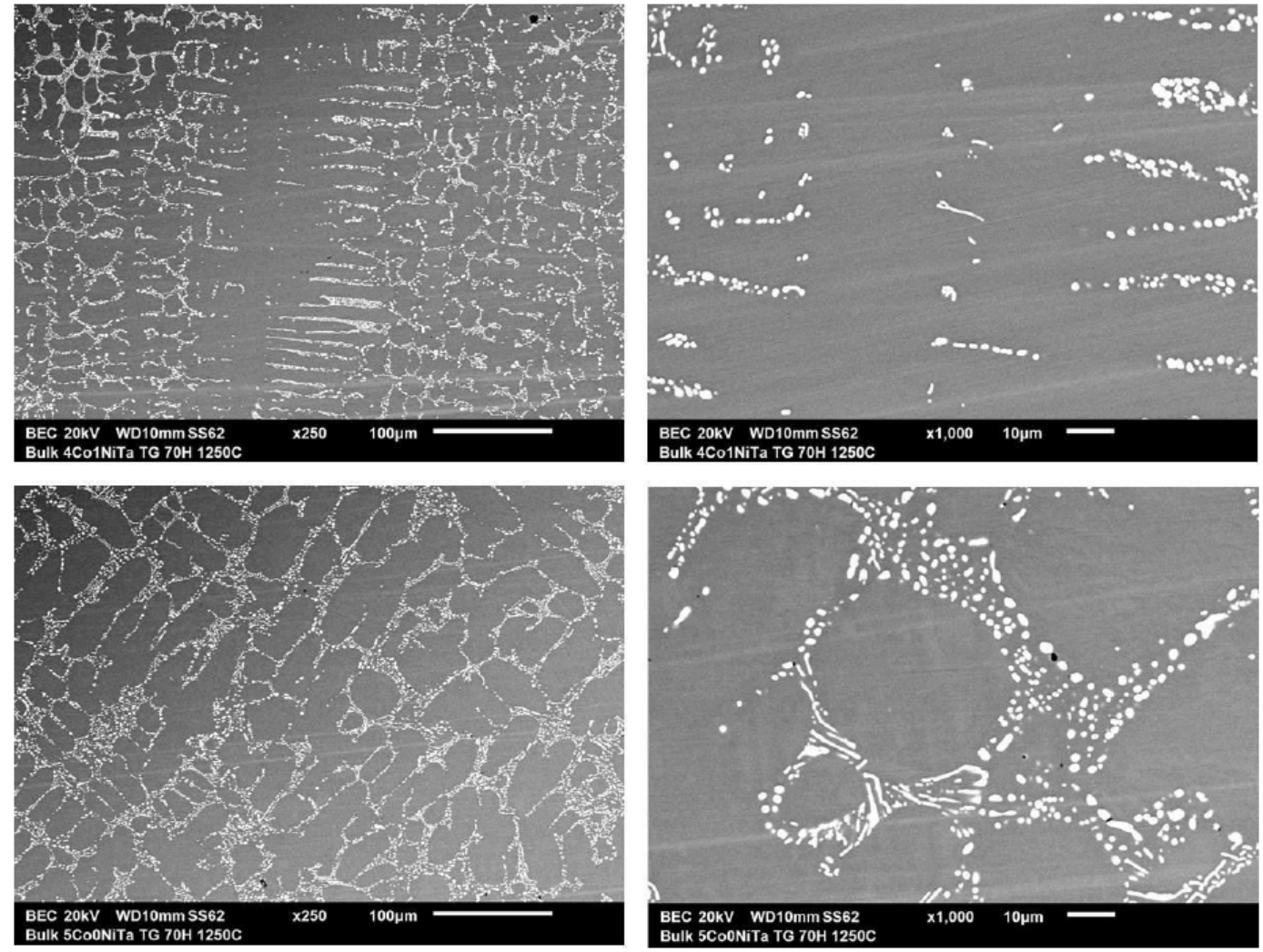

Figure 12: The new bulk microstructures of the two cobalt-richest alloys (4Co1NiTa: top, 5Co0NiTa: bottom, $\times 250$ : left, $\times 250$ : right). 


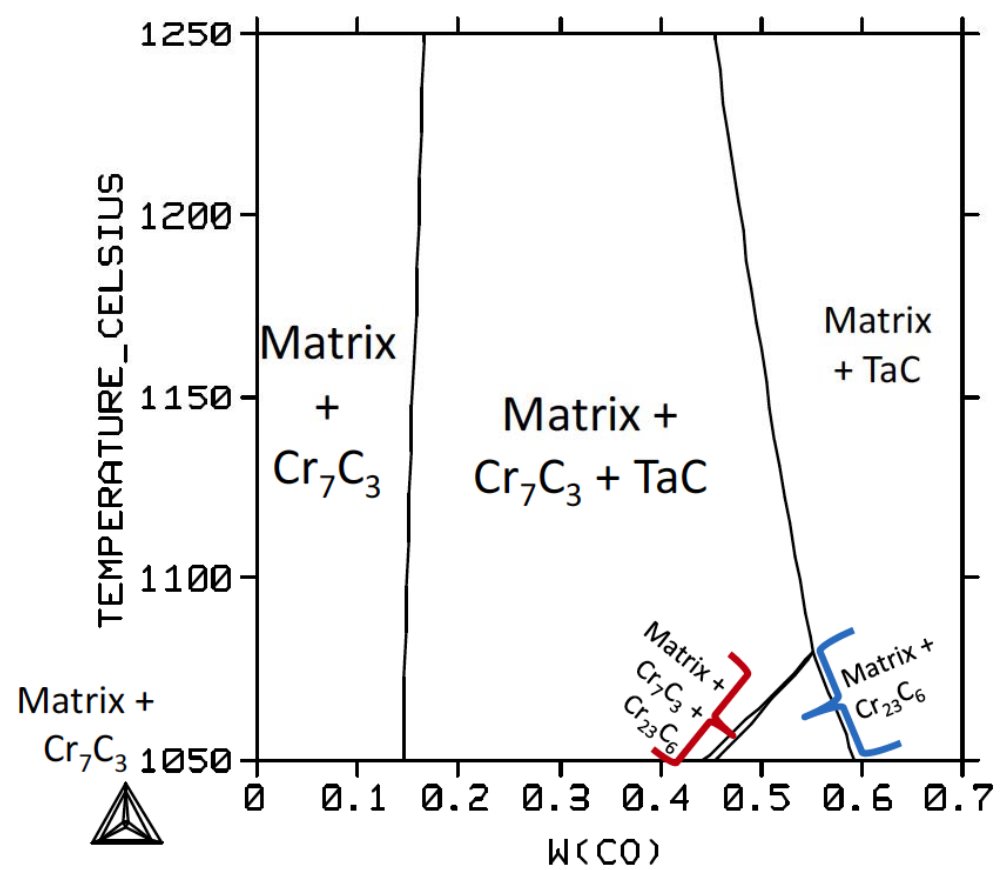

Figure 13: The high temperature solid state part of the isopleth section of the $\{\mathrm{Ni}, \mathrm{Co}, 25 \mathrm{wt} . \% \mathrm{Cr}, 0.4 \mathrm{wt} . \% \mathrm{C}, 6 \mathrm{wt} . \% \mathrm{Ta}\}$ diagram.

temperature oxidation behavior of these cast alloys especially rich in tantalum and based on varying proportions in nickel and cobalt. First the tendency to more severe spallation during cooling, and therefore to less resistance in case of thermal cycling, was deeper investigated by identifying the oxides present on surface and the ones formed in the subsurface. The $\mathrm{NiO},(\mathrm{Co}, \mathrm{Ni}) \mathrm{O}$ and $\mathrm{CoO}$ initially present on the outermost side of the oxide scales, as well as the spinel oxides of the $(\mathrm{Ni}, \mathrm{Co}) \mathrm{Cr}_{2} \mathrm{O}_{4}$ or $\mathrm{CoCr}_{2} \mathrm{O}_{4}$ types were lost with the spallation of chromia spallation, while the major part $\mathrm{CrTaO}_{4}$ oxide remained trapped in the extreme part of the sub-surface. It appears probable that this oxide of $\mathrm{Cr}$ and $\mathrm{Ta}$ is responsible to a lack of adherence of the external scale. This caused more severe spallation of the scale in the case of the nickelrichest alloys for which free Ta present in solid solution (more than in the cobalt alloys for which a major part of $\mathrm{Ta}$ is involved in carbides) is more mobile and leads to more $\mathrm{CrTaO}_{4}$ oxide at the interface. Because of the spallation that it caused a great part of this oxide may have been lost itself. On another side the best resistance of the $\mathrm{TaC}$ carbides against fragmentation and coalescence observed in the bulk of the cobaltrichest alloys suggests better mechanical properties at elevated temperatures.

So, despite the problem of slow $\mathrm{Cr}$ diffusion in Corich matrix which threatens the isothermal oxidation resistance of the cobalt-richest alloys, these alloys are, at $1250^{\circ} \mathrm{C}$, potentially stronger than the nickel-based ones in term of cyclic oxidation resistance and creep resistance.

\section{REFERENCES}

[1] Sims CT, Hagel WC. The superalloys. New York: John Wiley \& Sons 1972.

[2] Bradley EF. Superalloys: A Technical Guide. Metals Park: ASM International 1988.

[3] Donachie MJ, Dionachie SJ. Superalloys: A Technical Guide ( $2^{\text {nd }}$ edition), ASM International, Materials Park 2002.

[4] Opiekun Z. Journal of Materials Science 1987; 22(5): 1547. https://doi.org/10.1007/BF01132373

[5] Karge L, Gilles R, Mukherji D, Strunz P, Beran P, Hoffman M, Gavilano J, Keiderling U, Dolotko O, Kriele A, Neubert A. Roesler J, Petry W. Acta Materialia 2017; 132: 354. https://doi.org/10.1016/j.actamat.2017.04.029

[6] Buchanan ER, Tarshis LA. Metallurgical Transactions 1974; 5(6): 1413. https://doi.org/10.1007/BF02646627

[7] Woodford DA. Metallurgical Transactions A: Physical Metallurgy and Materials Science 1977; 8A(4): 639. https://doi.org/10.1007/BF02676987

[8] Gui W, Zhang H, Yang M, Jin T, Sun X, Zheng Q. Journal of Alloys and Compounds 2017; 695: 1271. https://doi.org/10.1016/j.jallcom.2016.10.256

[9] Kosftad P. High temperature corrosion. London: Elsevier applied science 1988.

[10] Young DJ. High Temperature Oxidation and Corrosion of Metals, Elsevier, Amsterdam 2008.

[11] Gozzi D, Guzzardi G, Montozzi M, Cignini PL. Solid State ionics 1997; 101-103(2): 1243. https://doi.org/10.1016/S0167-2738(97)00413-X

[12] Szoekefalvi-nagy A, Jehn H. Zeitschrift für Metallkunde 1984; 75(5): 389.

[13] Matsushiota J, Takeuchi K. Journal of Advanced Science 1998; 10(2\&3): 100.

https://doi.org/10.2978/jsas.10.2-3 100 
[14] Aranda L, Berthod P, Gomis J-PK, Himeur Z. Journal of Materials Science and Technology Research 2019; 6: 53-62. https://doi.org/10.15377/2410-4701.2019.06.7

[15] Berthod P, Aranda L, Medjahdi G, Gomis J-PK. Journal of Materials Science and Technology Research 2019; 6: 63-72. https://doi.org/10.15377/2410-4701.2019.06.8

[16] Thermo-Calc Version N. Foundation for Computational Thermodynamics, Stockholm, Sweden, Copyright, 1993, 2000. www.thermocalc.com
[17] SSOL Database, SGTE Solutions Database, Scientific Group Thermodata Europe, Bo Sundman, Stockholm, Sweden, 1992.

[18] Michon S. PhD thesis, University Henri Poincaré Nancy I, 2004.

Received on 14-10-2019

Accepted on 17-10-2019

Published on 25-10-2019

DOI: https://doi.org/10.31875/2410-4701.2019.06.9

(C) 2019 Gomis et al.; Zeal Press

This is an open access article licensed under the terms of the Creative Commons Attribution Non-Commercial License (http://creativecommons.org/licenses/by-nc/3.0/) which permits unrestricted, non-commercial use, distribution and reproduction in any medium, provided the work is properly cited. 